\title{
Evaluating a Tangible Game Video Console for Kids
}

\author{
Javier Marco, Eva Cerezo, and Sandra Baldassarri \\ Advanced Computer Graphics Group (GIGA) \\ Computer Science Department, Engineering Research Institute of Aragon (I3A) \\ University of Zaragoza, Spain \\ \{javi.marco, ecerezo, sandra\}@unizar.es
}

\begin{abstract}
Tangible and tabletop interaction can be suitable for kindergarten children as educational material, expressive tool, or merely for fun. But only playfully interactive experiences will happen if technologies include aspects that are relevant to the child's development, incorporating social experiences and easy control. Observation of children using these technologies is an important feedback to improve designs but an appropriated method has to be used in the evaluations. The Structured Expert Evaluation Method (SEEM) not only assesses technologies' usability but also fun aspects. This paper presents our research about the design and evaluation of a tabletop prototype oriented to children between 3 and 6 years, and the analysis of observations of children using our games.
\end{abstract}

Keywords: Tangible Interaction, Children Usability, Tabletop, User Center Design, SEEM, Games, Augmented reality.

\section{Introduction}

The educational and playful possibilities offered by tangible technologies are nowadays clear [8]. For the youngest, sympathetic interfaces such as "StoryMat" [4] and "Swamped!" [5] make use of toys in physical storytelling games. Other works, such as the "I/O Brush" [7] technologically enhance children toys for creativity and fun. Tabletop applications suitable for kindergarten children are less common, since interaction usually requires fine hand control that children less than 6 years old have not already achieved [6].

Our research intends to explore tabletop interaction possibilities with children between 3 and 6 years through the manipulation of physical toys avoiding multi-touch interaction problems. The design prototype described in this paper goes beyond common tabletop constraints with a low cost hardware, easily mountable and dismountable on kindergarten and schools rooms. During the design process periodical evaluation sessions were performed with small groups of children in order to observe and analyze the usability and fun of the tabletop prototype and games. The sessions were structured with the SEEM method [1] and after analysing their results general design recommendations can be obtained.

T. Gross et al. (Eds.): INTERACT 2009, Part I, LNCS 5726, pp. 141-144, 2009.

(C) IFIP International Federation for Information Processing 2009 


\section{NIKVision Description}

As our prototype would be mainly used by small children, it was needed to be robust, safe, and suitable in size: $70 \mathrm{~cm} \times 70 \mathrm{~cm}$ surface table and a height of $45 \mathrm{~cm}$ (see fig.1). Interaction is carried out manipulating toys over the table surface. Visual recognition software [3] translates the physical condition of the table into a $3 \mathrm{D}$ virtual environment implemented with [2] and shown on the TV. In addition, it is possible to project images on the tabletop in order to georeference guidance.
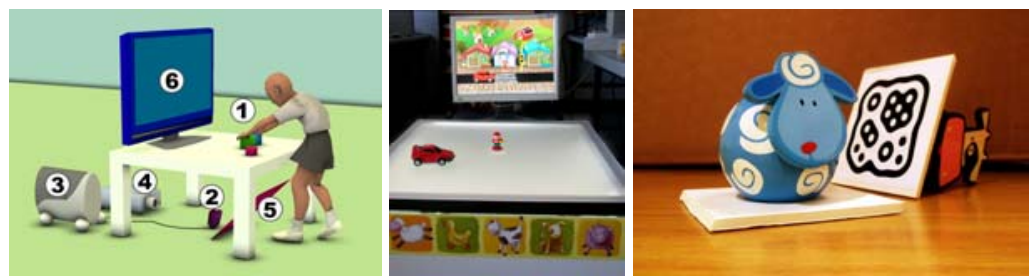

Fig. 1. Left: Tabletop prototype sketch: 1. Diffuse tabletop surface with toys. 2. USB webcam. 3. PC computer with Tabletop software. 4. Video projector for tabletop image output. 5. Mirror for projection under the table surface. 6. TV set with speakers for image and audio output. Center: Tabletop working. Right: Toys with fiducials used by recognition software.

\section{Evaluating Tabletop Games with SEEM}

While designing our tabletop and games one of our worries was to bring up, as soon as possible, usability problems. Therefore, we carried out periodical tests with children, that were structured with the help of SEEM questionnaires. SEEM questions focus on game goals, and how children perceive them in two aspects: usability and fun (see Table 1).

Table 1. SEEM questionnaire by categories

\begin{tabular}{|c|c|c|}
\hline Category & Usability questions & Fun questions \\
\hline GOAL & $\begin{array}{l}\text { Can children perceive and } \\
\text { understand the goal? }\end{array}$ & $\begin{array}{l}\text { Do children think the } \\
\text { goal is fun? }\end{array}$ \\
\hline $\begin{array}{l}\text { PLANNING AC- } \\
\text { TIONS }\end{array}$ & $\begin{array}{l}\text { Children perceive and } \\
\text { understand the actions they } \\
\text { have to execute in order to } \\
\text { reach the goal? }\end{array}$ & $\begin{array}{l}\text { Do children think the } \\
\text { actions they have to } \\
\text { execute in order to reach } \\
\text { the goal are fun? }\end{array}$ \\
\hline $\begin{array}{l}\text { PHYSICAL AC- } \\
\text { TIONS }\end{array}$ & $\begin{array}{l}\text { Are children able to per- } \\
\text { form the physical actions } \\
\text { easily? }\end{array}$ & \\
\hline FEEDBACK & $\begin{array}{l}\text { Can children perceive and } \\
\text { understand the feedback (if } \\
\text { any)? }\end{array}$ & $\begin{array}{l}\text { Is the negative / positive } \\
\text { feedback motivating? }\end{array}$ \\
\hline
\end{tabular}


Sessions were video recorded with two cameras: one took the TV image of the game evolution, and the other took the children actions with the toys over the tabletop. Additionally, the software recorded the toy's paths on the table during the game.

A competitive game, "Collecting strawberries", was used to detect interaction problems. The 3D scenery is a field with several plants (see fig. 2). Each of the two players chooses one farm animal to play with. Some plants hide strawberries and children compete for collecting them. To do this, children have to move the toy animals onto a plant location. Here, we will briefly explain the problems observed during the test sessions, grouped by the SEEM category, and the solutions that were carried out to solve them.
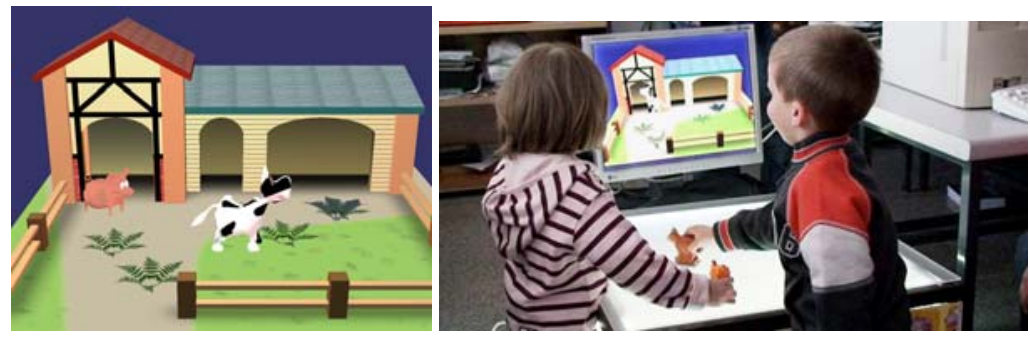

Fig. 2. The "Collecting strawberries" game

Physical actions: It is important that children can handily play on the tabletop. At the beginning, children showed difficulties in reaching the far side of the table. Several modifications of the tabletop design were carried out in order to improve this. On the other hand, children had doubts on how to move the animals to collect the strawberries. On the original game version, strawberries were collected by simply getting closer to the plants. Therefore, in the game final version the children shake the virtual plants with the toys in order to drop the fruits. This kind of movements, that have to be natural, improves the fun element of the game.

Planning actions: In the first tests, children did not have georeferenced help on the table surface to locate the plants, only the virtual scene on the TV. Children showed difficulties on moving the animals to the right place (see fig.3.left). So, tabletop projection on the game with georeferenced help was implemented to locate the plants. In the new tests, children were able to locate plants faster (see fig.3.right), and fun was improved.
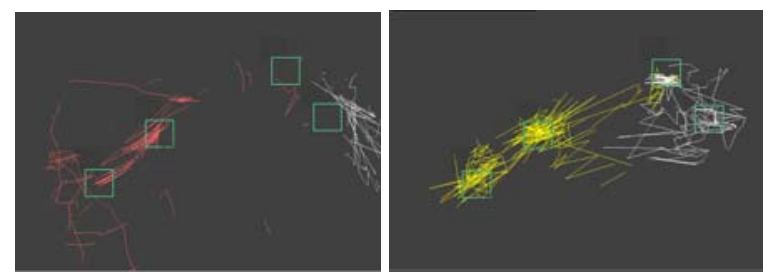

Fig. 3. Recorded graphs showing the paths followed by the toys in the strawberries game. Left: No georeferenced game. Right: Georeferenced game. The squares represent the plants location. 
Feedback: With very young children, positive and negative feedback becomes one of the main design aspects to consider. In our tabletop, as children need to divide their visual attention between tabletop image feedback and TV 3D scenery, sound becomes the best way of giving feedback. Short and funny sounds indicates if a strawberry has been found (positive feedback), or the plant is empty (negative feedback).

\section{Conclusions}

The main conclusions of our test sessions are the following:

- Test sessions must be carried out as soon as possible during the development of the games to detect misconceptions on the designs.

- It is important that children understand clearly the goals of the game. However, giving to much details and instructions rests fun as they would only follow the steps. Letting them to explore and discover enhances fun and thus, learning.

- In this freely conditions, feedback (sound and georeference) is crucial, enabling the children to know in every moment if they are doing right or wrong.

\section{Acknowledgements}

This work has been partly financed by the Spanish "Dirección General de Investigación", contract number $N^{\circ}$ TIN2007-63025 and by the Aragon Government through the Cooperation Projects between University and Secondary Education Departments (2008-2009) and the IAF N²008/0574 and CyT N²008/0486 agreements. We want to thank Janet Read, Emanuela Mazzone and Diana $\mathrm{Xu}$ of the ChiCI Group, at UCLAN University (UK) for their constant help and guidance.

\section{References}

1. Baauw, E., Bekker, M.M., Markopoulos, P.: Assessing the applicability of the structured expert evaluation method (SEEM) for a wider age group. In: Proceedings of the 2006 Conference on interaction Design and Children (2006)

2. Baldassarri, S., Cerezo, E., Serón, F.: Maxine: A platform for embodied animated agents. Computer \& Graphics 32(4), 430-437 (2008)

3. Bencina, R., Kaltenbrunner, M.: The Design and Evolution of Fiducials for the reacTIVision System. In: Proceedings of the Third International Conference on Generative Systems in the Electronic Arts (2005)

4. Cassell, J., Ryokai, K.: Making Space for Voice: Technologies to Support Children's Fantasy and Storytelling. Personal Technologies 5(3), 203-224 (2001)

5. Johnson, M.P., Wilson, A., Blumberg, B., Kline, C., Bobick, A.: Sympathetic interfaces: using a plush toy to direct synthetic characters. In: Proceedings of the SIGCHI Conference on Human Factors in Computing Systems (1999)

6. Mansor, E.I., De Angeli, A., De Bruijn, O.: Little fingers on the tabletop: A usability evaluation in the kindergarten. In: Horizontal Interactive Human Computer Systems (2008)

7. Ryokai, K., Marti, S., Ishii, H.: I/O brush: beyond static collages. In: CHI 2007 Extended Abstracts on Human Factors in Computing Systems (2007)

8. Zuckerman, O., Arida, S., Resnick, M.: Extending tangible interfaces for education: Digital Montessori inspired manipulatives. In: Proc. of CHI 2005, pp. 859-868. ACM Press, New York (2005) 